\title{
An analysis of visual-motor problems in learning disabled children
}

\author{
ROBERTA E. MATTISON, CURTIS W. MCINTYRE, \\ ALAN S. BROWN, and MICHAEL E. MURRAY \\ Southern Methodist University, Dallas, Texas
}

\begin{abstract}
The nature of visual-motor problems in learning disabled children was examined in four conditions designed to determine whether more errors were made by learning disabled children, and whether the errors were primarily perceptual, conceptual, motoric, or some combination of these in nature. The same two groups of children were used in each condition. One group contained 20 children (mean age $=10$ years, 7 months) who had been diagnosed as learning disabled. The control group contained 20 children who were matched with the learning disabled children on age, sex, IQ, and SES. The learning disabled children evidenced visual-motor problems under a visual-motor condition that was modeled after the Bender Visual Motor Gestalt Test. In three other conditions, the visual-perceptual, perceptual-conceptual, and motor-coordinative components of the visual-motor condition were examined separately. The results of these conditions indicated that the visual-perceptual and perceptual-conceptual components of the visual-motor system were intact for the learning disabled children; however, both the motor-coordinative component and the integration between the visual-perceptual and the motor-coordinative components were disturbed. The implications of these results for the visual-motor problems of learning disabled children were discussed.
\end{abstract}

Recent research has shown that perceptual disturbances are some of the most reliable indicators of learning disabilities (Cruickshank, 1977; Kephart, 1971; Ross, 1976). More specifically, one major subset of perceptual disturbances, visual-motor problems, has been mentioned repeatedly in the literature (Hallahan \& Cruickshank, 1973; Kephart, 1971; Meier, 1976; Ross, 1977). For example, previous work with two visual-motor tests, the Bender Visual Motor Gestalt Test and the Frostig Developmental Test of Visual Perception, has shown that learning disabled children make more errors than do their unaffected peers (Chissom, 1972; Frostig \& Horne, 1964); however, little is known about the nature of these errors. As a first step toward analyzing the nature of these errors, we identified 10 types of common errors which were made on the visual-motor parts of the WISC-R, Bender Gestalt, and Frostig tests: vertical rotation, horizontal rotation, diagonal rotation, perpendicular rotation, three-dimensional rotation, size constancy, figure-ground, integration, simplification, and perseveration-truncation.

Once these types of errors were identified, a number of questions remained. For example, when a learning disabled child makes a diagonal rotation error when copying a figure on the Bender Visual Motor Gestalt Test (see Koppitz, 1963), it is impossible, given the nature of the test, to determine where in the complex visual-motor

Requests for reprints should be sent to C. W. McIntyre, Department of Psychology, Southern Methodist University, Dallas, TX 75275. process this error was made. One possibility is that the child may have "seen" the figure as rotated by $45^{\circ}$ and copied what he "saw." A second possibility is that the child may have perceived the original stimulus correctly, but failed to form a correct concept or mental image of it. A third possibility is that the child may have perceived and conceptualized the original stimulus correctly but was unable to coordinate an accurate drawing of this mental image. Clearly, successful completion of this simple visual-motor task requires that the child be able to perceive, conceptualize, and draw the visual stimulus. Hence, this visual-motor process can be conceived as the integration of three major components: a visual-perceptual component, a perceptual-conceptual component, and a motorcoordinative component. This overall visual-motor process and each of its major components were investigated in the present study.

Each subject took part in four separate conditions, one corresponding to the overall visual-motor process, and the other three corresponding to each of the three major components. In the visual-motor condition, the presence of visual-motor problems in learning disabled children was demonstrated with simple visual stimuli (graphemes), similar to those used by Gibson, Gibson, Pick, \& Osser (1962). These problems were examined in more detail in the other three conditions, where each component of the visual-motor process (i.e., visual-perceptual, perceptualconceptual, and motor-coordinative) was examined separately. The order of presentation of these conditions was randomized for each child, and different graphemes were used under each condition. 


\section{METHOD}

\section{Subjects}

Forty children, ranging in age from 8 years, 8 months, to 12 years, 11 months (mean $=10$ years, 7 months), participated in all five conditions. Twenty of the children were diagnosed as learning disabled by a clinical psychologist and a pediatrician on the basis of a battery of standardized tests that measured perceptual-motor (Frostig Developmental Test of Visual Motor Integration, Bender Visual Motor Gestalt Test) and intellectual/academic skills (Weschler Intelligence Scale for ChildrenRevised, Wide Range Achievement Test). All the learning disabled children met the following criteria: (a) normal intelligence, ranging in IQ from 85 to 115 , as measured by the WISC-R; (b) absence of primary visual, motor, or hearing impairment; (c) absence of emotional disturbance as indicated by prior diagnosis; (d) absence of known organic impairment; (e) adequate educational, environmental, and cultural opportunities; and (f) evidence of a primary deficiency in language learning skills as reflected by at least a 1.5-year discrepancy between performance on either the Reading or the Spelling sections of the Wide Range Achievement Test (WRAT) and expected grade placement based on chronological age. A psychometric profile of the learning disabled children is given in Table 1.

\section{Stimuli and Procedures}

\section{Visual-Motor Condition}

A grapheme copying task, similar in administration to the Bender Visual Motor Gestalt Test, was used. In this condition, each child was asked to draw a simple grapheme.

Practice trials. On each of five trials, an English letter was presented, and the child was asked to copy it in the blank square provided. Each trial was presented on a separate page. The practice trials were not scored.

Experimental trials. During the experimental trials, the procedure was similar. Each child was given 20 trials in which a grapheme was presented, and the child was asked to copy it in the blank square provided. The 20 trials ( 1 for each of the two graphemes transformed by each of the 10 error types) were presented in a random order on separate pages. Each trial was scored on an all-or-nothing basis; thus, the score possible for each subject ranged from 0 (no correct responses) to 20 (no errors).

During all of the experimental conditions, encouragement and repetition of the instructions were provided, but no indication of the correctness of the child's responses was given. A standard red pencil was provided and erasures were allowed.

\section{Visual-Perceptual Condition}

The purpose of this condition was to assess the ability of the children to perceive visual stimuli accurately. A visual match-to-sample task was used. In this condition, each child was asked to select target graphemes from an array containing both duplicate target graphemes and graphemes transformed by the 10 error types.

Practice trials. On each of the five practice trials, the child was asked to select the duplicate of a target English letter from an array that contained five English letters. The English letters were presented in 2-in. slide mounts. The practice trials were not scored.

Experimental trials. During the experimental trials, the procedure was similar. Each child was asked to select the six duplicates of two

Table 1

Psychometric Profile of the Learning Disabled Group

\begin{tabular}{lcrrr}
\hline \multicolumn{1}{c}{ Source } & N & Mean & \multicolumn{1}{c}{ SD } & SE \\
\hline Age & 20 & 10.74 & 1.45 & .35 \\
Chronological Grade Placement & 20 & 5.35 & 1.37 & .33 \\
WISC-R (Full Scale IQ) & 20 & 99.15 & 12.50 & 2.79 \\
WISC-R (Verbal IQ) & 20 & 98.25 & 12.84 & 2.87 \\
WISC-R (Perfor mance IQ) & 20 & 100.70 & 14.20 & 3.17 \\
WRAT (Word Recognition)* & 20 & 4.88 & 2.02 & .45 \\
WRAT (Spelling)* & 20 & 4.10 & 1.51 & .34 \\
WRAT (Arithmetic)* $^{*}$ & 20 & 3.85 & .63 & .14 \\
\hline
\end{tabular}

*(Jastak, Bijou, \& Jastak, 1978) target graphemes from an array that contained the six duplicates, three of each standard, plus 20 transformations of the two target graphemes (10 of each). The duplicates of the target graphemes and the 20 transformed graphemes were ordered randomly within the array and presented in 2 -in. slide mounts. The number of errors made by the child was recorded. The possible scores ranged from 0 (no correct responses) to 20 (no errors).

\section{Perceptual-Conceptual Condition}

The purpose of this condition was to assess the ability of the children to generate an accurate concept of a visual stimulus. A conceptual matching task was used. In this condition, each child was asked to select a grapheme that was transformed via 1 of the 10 error types from among an array containing all 20 error types.

Practice trials. On each of five practice trials, a standard English letter was matched with the same letter in stylized form, while a second English letter was presented. The child was asked to choose the appropriate stylized form of the second letter from an array which contained five stylized forms of the same letter. Each trial was presented on a separate page. The practice trials were not scored.

Experimental trials. During the experimental trials, the procedure was similar. Each child was given 20 trials in which a grapheme was matched with an English letter (two graphemes and two letters were used). On each trial, the English letter was transformed by one of the 10 error types. The child was asked to choose the transformed grapheme that was analogous to the transformed English letter from an array containing 10 transformed graphemes. The 20 trials ( 1 for each of the 2 graphemes that underwent each of the 10 transformations) were presented in a random order. The order of the transformed graphemes in the selection array was randomized for each trial. Each trial was presented on a separate page and scored on an all-or-nothing basis; the score possible for each subject ranged from 0 (no correct responses) to 20 (no errors).

\section{Motor-Coordinative Condition}

The purpose of this condition was to assess the ability of the children to coordinate the motor production required for the simple paper-andpencil tasks used in the present study. A simple grapheme tracing task was used.

Practice trials. On each of five practice trials, the child was asked to trace over an English letter. The five English letters were presented together on a single page; each letter was contained within a 2 -in. black border square. The practice trials were not scored.

Experimental trials. During the experimental trials, the procedure was similar. Each child was given 20 trials presented on two pages (10 on each page). Each page contained 102 -in. squares with a single grapheme in each. The 20 graphemes used consisted of two standard graphemes transformed by each of the 10 error types (10 for each grapheme). The child was asked to trace over the transformed graphemes. Each trial was scored on an all-or-nothing basis; the score possible for each child ranged from 0 (no correct responses) to 20 (no errors). Erasures were not allowed.

\section{RESULTS AND DISCUSSION}

The basic data were the numbers of correct responses made by the learning disabled children and their matched controls under each condition. A 2 (groups) $\times 4$ (conditions) ANOVA applied to these data recorded significant main effects for groups $[F(1,38)=8.35, p<.01]$, for conditions $[F(3,114)=3.89, p<.02]$, and for a groups $\times$ conditions interaction $[F(3,114)=5.48, p<.01]$. The significant main effect for groups indicates that the mean number of correct responses made by the normal controls (16.55) was higher than that made by the learning disabled subjects (14.99). Application of NewmanKeuls multiple comparison tests $(p<.05)$ to the signifi- 
Table 2

The Mean Number of Correct Responses

\begin{tabular}{lccc}
\hline & \multicolumn{3}{c}{ Means } \\
\cline { 2 - 4 } \multicolumn{1}{c}{ Condition } & $\begin{array}{c}\text { Learning } \\
\text { Disabled }\end{array}$ & $\begin{array}{c}\text { Normal } \\
\text { Controls }\end{array}$ & Both \\
\hline Visual-Motor & 12.55 & 17.85 & 15.20 \\
Visual-Perceptual & 16.85 & 17.05 & 16.95 \\
Perceptual-Conceptual & 14.75 & 15.45 & 15.10 \\
Motor-Coordinative & 13.80 & 15.85 & 14.83 \\
All & 14.49 & 16.55 & 15.52 \\
\hline
\end{tabular}

cant main effect for conditions revealed that the mean number of correct responses obtained for the visualperceptual condition (16.95) was higher than those obtained for the other three conditions $(15.20,15.10$, and 14.83 for the visual-motor, perceptual-conceptual, and motor-coordinative conditions, respectively). Application of Cicchetti (1972) multiple comparison tests $(p<.05)$, which allow the direct pairwise comparison of unconfounded means within the groups $\times$ conditions interaction table (see Table 2), revealed that the normal controls did significantly better than the learning disabled subjects under the visual-motor and the motor-coordinative conditions; the learning disabled subjects did significantly better under the visual-perceptual and perceptual-conceptual conditions than they did under the visual-motor condition; and, the normal controls did significantly better under the visual-motor condition than they did under the perceptualconceptual condition.

The results obtained under the visual-motor condition indicate that when learning disabled children draw visual stimuli, their performances are significantly poorer than those of their matched controls. As discussed before, this condition involves visual-perceptual, perceptualconceptual, and motor-coordinative components. The relative contributions of each of these components to the errors made in the visual-motor condition are reflected in the results of the other three conditions. The results obtained under the visual-perceptual condition indicate that when learning disabled children match visual stimuli, their performances are similar to those of their matched controls. Similarly, the results obtained under the perceptualconceptual condition indicate that when learning disabled children apply a mental transformation to a visual stimulus, their performances are similar to those of their matched controls. In contrast, the results obtained under the motor-coordinative condition indicate that when learning disabled children trace a visual stimulus, their performances are significantly poorer than those of their matched controls. Evidently, learning disabled children have motor-coordinative difficulties that contribute to the errors obtained on the simple paper-and-pencil tasks used in the visual-motor condition.

In a series of covariate analylses, the visual-perceptual, perceptual-conceptual, and motor-coordinative components were separately partialed out of the visual-motor results. None of these three analyses changed the pattern of results; that is, the normal controls always performed significantly better than the learning disabled subjects. Since the subject must be able to perceive the visual stimulus accurately in order to be able to trace it, both the visual-perceptual and the motor-coordinative components were partialed out of the visual-motor results in an additional covariate analysis. Again, the pattern of results remained the same; the normal controls performed significantly better than the learning disabled subjects.

One possible explanation of these results is that the isolated visual system is intact, but that the higher level intersensory, or cross-modal, integration across the visual and motor modalities is disturbed. Cross-modal or intersensory integration involves the summation or integration of sensations originating from separate sensory channels. Therefore, a deficit in integrative function could result in a discrepancy between the sensory input and the motor output. Learning disabled children evidenced this disturbance by performing well on tasks requiring visual ability, but failing to accurately complete tasks that required simultaneous visual and motor ability.

In the past, research from three separate areas has implicated cross-modal integration in the problem evidenced by learning disabled children. First, the high incidence of reading difficulties within learning disabled populations has indicated a possible disturbance of visual-auditory integration, since both modalities are involved in learning to read (Birch \& Belmont, 1965). Second, marked impairment in all forms of written expression has been observed consistently by investigators working with children who have been diagnosed as neurologically impaired, brain-injured, dyslexic, or learning disabled (Boder, 1971; Lerner, 1971; Myers \& Hammill, 1969; Myklebust, 1973; Saunders, 1962). More specifically, Myklebust (1973) has attributed the difficulties these children have with written language partially to deficits in visual-motor integration. Third, retarded readers perform significantly more poorly than normal readers on tasks requiring crossmodal integration (Birch \& Belmont, 1965; Blank \& Bridger, 1966; Muehl \& Kremanak, 1966; Senf, 1969; Senf \& Freundl, 1971). The implications of these studies are that there are direct correlations between reading difficulties and cross-modal integrative disturbances.

The present study has important implications for the remediation of the visual-motor problems of learning disabled children and for the development of a visual-motor diagnostic instrument. Turning first to the remediation of visual-motor problems in learning disabled children, the results indicate that motor coordination should receive special attention. Special training aimed at helping the child develop increased hand-eye motor coordination and general body control as well as basic motor concepts (e.g., directionality and spatial position) should be developed to aid in their overall visual-motor development. Turning next to the development of a visual-motor diagnostic instrument, it is clear from the present results that future efforts should be aimed at the development of a diagnostic instrument that would assess perceptual, conceptual, and motoric components within the overall context of 
visual-motor evaluations. Of course, this would require detailed item analyses, more detailed analyses of the errors found, and extensive validity, reliability, and standardization procedures. Fortunately, the results obtained in the present research indicate that efforts in both these directions would prove most fruitful.

\section{REFERENCES}

BirCH, H., \& BELMONT, L. (1965). Auditory-visual integration, intelligence, and reading ability in school children. Perceptual \& Motor Skills, 20, 295-305.

Blank, M., \& BRIDGER, W. (1966). Deficiencies in verbal labeling in retarded readers. American Journal of Orthopsychiatry, 36, 840-847.

BoDER, E. (1971). Developmental dyslexia: Prevailing diagnostic concepts and a new diagnostic approach. In H. R. Myklebust (Ed.), Progress in learning disabilities (Vol. 2). New York: Grune \& Stratton.

CHISsom, B. S. (1972). Review of Frostig DTVP. In O. K. Buros (Ed.), The seventh mental measurements yearbook (Vol. II). Highland Park, NJ: The Gryphon Press.

Cichetti, D. V. (1972). Extension of multiple-range tests to interaction tables in the analysis of variance: A rapid approximate solution. Psychological Bulletin, 77, 405-408.

Cruickshank, W. M. (1977). Learning disabilities in home, school, and community. New York: Syracuse University Press.

Frostig, M., \& HoRne, D. (1964). The Frostig program for the development of visual perception. Chicago: Follett.

Gibson, E. J., Gibson, J. J., Pick, A. D., \& Osser, H. A. (1962). Developmental study of the discrimination of letter-like forms. Journal of Comparative \& Physiological Psychology, 55, 897-906.
Hallahan, D. P., \& Cruickshank, W. M. (1973). Psychoeducational foundations of learning disabilities. Englewood Cliffs, NJ: Prentice Hall.

JASTAK, J. K., BIJOU, S. W., \& JASTAK, S. (1978). The wide range achievement test. Wilmington: Jastak.

KEPHART, N. C. (1971). The slow learner in the classroom (2nd ed.). Columbus, Ohio: Merrill.

KoppITZ, E. M. (1963). The Bender Gestalt Test for young children. New York: Grune \& Stratton.

LERner, J. W. (1971). Children with learning disabilities: Theories, diagnoses and teaching strategies. Boston: Houghton-Mifflin.

Meier, J. H. (1976). Developmental and learning disabilities. Baltimore: University Park Press.

Muehl, S., \& KremanaK, S. (1966). Ability to match information within and between auditory and visual sense modalities and subsequent reading achievement. Journal of Educational Psychology, 57, 230-239.

Myers, P. I., \& HammiLl, D. D. (1969). Methods for learning disorders. New York: Wiley.

MYKLEBUST, H. R. (1973). Development and disorders of written language: Studies of normal and exceptional children (Vol. 2). New York: Grune \& Stratton.

Ross, A. O. (1976). Psychological aspects of learning disabilities and reading disorders. New York: McGraw-Hill.

Ross, A. O. (1977). Learning disability. New York: McGraw-Hill.

SAUNDERS, R. E. (1962). Dyslexia: Its phenomenology in reading disability: Progress and research needs. In J. Money (Ed.), Dyslexia. Baltimore: Johns Hopkins Press.

SENF, G. M. (1969). Development of immediate memory for bisensory stimuli in normal children and children with learning disorders. Developmental Psychology, 1, 1-28.

SENF, G. M., \& FREUNDL, P. C. (1971). Memory and attention factors in specific learning disabilities. Journal of Learning Disabilities, 4, 94-106.

(Manuscript received for publication September 17, 1985.) 